Indexed by

\title{
Scopus
}

\section{INCORPORATING AN OUTSOURCING STRATEGY AND IN-HOUSE QUALITY ASSURANCE INTO THE PRODUCTION-SHIPMENT DECISION MAKING}

Crossref

\section{Singa Wang Chiu}

Chaoyang University of Technology, Department of Business Administration, Taichung, Taiwan

\section{Hong-Dar Lin}

Chaoyang University of Technology, Department of Industrial Engineering \& Management, Taichung, Taiwan

\author{
Yi-Ying Li \\ Chaoyang University of \\ Technology, Department \\ of Industrial Engineering \& \\ Management, Taichung, \\ Taiwan
}

\author{
Victoria Chiu \\ State University of New York \\ at Oswego, Department of \\ Accounting, Finance and Law, \\ Oswego, USA
}

KOBSON
Key words: production and operation management, replenishment lot-size, multiple shipments, outsourcing, product quality assurance doi:10.5937/jaes0-31313

Cite article:

Wang Chiu S., Li Y., Chiu V., Lin H. (2022) INCORPORATING AN OUTSOURCING STRATEGY AND IN-HOUSE QUALITY ASSURANCE INTO THE PRODUCTION-SHIPMENT DECISION MAKING, Journal of Applied Engineering Science, 20(1), 212 - 220, DOI:10.5937/ jaes0-31313

Online aceess of full paper is available at: www.engineeringscience.rs/browse-issues 


\title{
INCORPORATING AN OUTSOURCING STRATEGY AND IN-HOUSE QUALITY ASSURANCE INTO THE PRODUCTION-SHIPMENT DECISION MAKING
}

\author{
Singa Wang Chiu', Yi-Ying Lí2, Victoria Chiü, Hong-Dar Lin ${ }^{2, *}$ \\ ${ }^{1}$ Chaoyang University of Technology, Department of Business Administration, Taichung, Taiwan \\ ${ }^{2}$ Chaoyang University of Technology, Department of Industrial Engineering \& Management, Taichung, \\ Taiwan \\ ${ }^{3}$ State University of New York at Oswego, Department of Accounting, Finance and Law, Oswego, USA
}

To stay competitive in turbulent business environments, manufacturing firms' managers today constantly seek ways to reduce order response time, smooth production schedules, ensure the quality of their products, and lower overall making and shipping costs. This study incorporates an outsourcing strategy and in-house quality assurance into a production-shipment problem to address the aforementioned operational goals. The objectives are to simultaneously find the optimal fabrication batch size and frequency of delivery that minimize the system's relevant costs and reveal in-depth information regarding the impact of diverse system parameters on the optimal policy and system cost. This study develops a model and uses the optimization method to resolve the problem. The research results facilitate managerial decisions in such a real-life situation.

Key words: production and operation management, replenishment lot-size, multiple shipments, outsourcing, product quality assurance

\section{INTRODUCTION}

This study incorporates outsourcing and in-house quality assurance matters into production-shipment decision-making. Outsourcing for meeting product demand is a helpful strategy often used by the management of manufacturing firms to resolve occasional capacity short supply, shorten replenishment cycle (response) time, or smooth production schedules, or reduce overall system cost. Leavy [1] reviewed the increasing influences of business strategies in present-day's companies, including outsourcing, with a focus on the perception of learning in strategic analysis. Chalos and Sung [2] presented a model wherein outsourcing takes over in-house fabrication, and they argued that outsourcing could increase managerial incentives. They set up situations for a producer who favors applying the outsourcing, and their study included having outsourcers for publicly and privately held corporations. As a result, the researchers offered diverse comments on outsourcing practices. Levina and Ross [3] studied the potential values gained from outsourcing information technology (IT). They carefully examined IT vendor strategy and practices from a successful outsourcing contract. They found that a vendor can derive economic profits from its capability of developing a fine set of core competencies through a variety of its IT projects. Based on these findings and existing knowledge of the client-vendor relationship, they suggested ways to assess IT outsourcing's values. Serrato et al. [4] used a Markov decision to investigate outsourcing in reverse logistics functions (RLF), especially if returns are unsteady. Using capacity and operation cost as reward function, they constructed an analytical Markov model for outsourcing decision-making on either carrying out RLF in-house or outsourcing them. Accordingly, the researchers identified some sufficient conditions on system parameters to ensure an optimal outsourcing policy. Proff [5] explored the competencies shift from automobile manufacturers to module suppliers in components outsourcing policy, especially for those manufacturers who implemented differentiation strategy. Based on core competency and transaction cost theories, the researcher recommended a few possible tactical actions. Balachandran et al. [6] studied the influence of in-house fabrication capability on supply chain decisions. Different scenarios regarding the producer's in-house ability and its outsourcer's incentive to invest in the fabrication process were carefully examined and discussed. The authors revealed the effect of in-house capability on supply chain interdependent decisions and efficiencies. Additional articles [7-11] also studied various features of outsourcing options on manufacturing and supply-chain systems.

Maintaining high and steady product quality is one of the essential operation goals in most manufacturing firms. Production of faulty items is inevitable owing to different factors in the fabrication process. The capabilities of identifying and removing the scrap items, and reworking the repairable products, are significant tasks in quality management. Rosenblatt and Lee [12] explored the lot sizing for an economic production quantity (EPQ) model with stochastic nonconforming produced in the manufacturing process's out-of-control state. The researchers 
presented fairly accurate solutions for optimal lot-size. Rahim and Ben-Daya [13] investigated the combined effects of arbitrary deteriorating products and fabrication processes on the EPQ policy, optimal schedule for inspection, and quality control procedure. They used numerical examples to express and explain their models and results. Ojha et al. [14] studied a quality assured integrated fabrication-inventory problem including supplier, producer, and customer. Their model assumed a constant defective rate and a rework process. The entire lot has to be quality assured before distribution to the customer. Various scenarios were presented and examined to decide the optimal operating policies. Additional studies that explored diverse features of quality assurance matters in fabrication systems can also be referred to [15-19].

As assumed in this study, multiple shipments policy is practically employed in most supply chain systems for transporting stocks, unlike the continuous inventory issuing policy described in the classic EPQ model [20]. Goyal [21] presented an approach to solving a single-vendor, single-buyer supply chain system. Through illustrative examples, the author confirmed his proposed solution procedure. Banerjee [22] explored a customer-vendor integrated EPQ model intending to minimize the combined system cost. The author commented that a price adjustment consideration in ordering decision-making could benefit both parties. Viswanathan [23] studied vendor-buyer integrated inventory systems using two distinct strategies extracted from past literature. The first one assumes fixed quantity delivery, and the other considers the delivery of the vendor's all available stocks. Through in-depth numerical illustrations that provide various performance indicators of these strategies, the study concluded that no one approach gave the best solution to the problem's potential variables. Sarker and Diponegoro [24] explored a multi-supplier single-producer multi-customer integrated supply chain system. Their system purchased raw materials from multiple non-competing suppliers and shipped the finished goods to various buyers at a constant time interval. Their objectives were to decide the optimal procurement, production, and shipment strategies that minimize the combined system costs. Additional works that investigated diverse features of multi-shipment policies in different aspects of supply chain systems can be found elsewhere [25-29]. Since few studies focused on exploring the combined effects of outsourcing, in-house quality assurance matters, and multiple deliveries on the optimal fabrication-delivery policy, this paper aims to fill the gap.

\section{ASSUMPTIONS, MODELLING, AND FORMULATIONS}

The proposed EPQ-based system incorporates outsourcing and in-house quality assurance into production-shipment decision making to meet the annual demand $\lambda$. A $\pi$ proportion of the lot size $Q$ (where $0<\pi<$ 1 ) is outsourced in each cycle, i.e., (1-ח)Q amount is made in-house. The outside provider guarantees the quality of outsourcing products, and the receiving time of outsourced items is set at the end of in-house rework time (refer to Figure 1). Relevant costs associated with the outsourcing portion include fixed setup cost $K_{\pi}$ and variable outsourcing cost $C_{\pi}(\pi Q)$, where $K_{\pi}=\left[\left(1+\beta_{1}\right) K\right]$, $C_{\pi}=\left[\left(1+\beta_{2}\right) C\right]$, and $K$ and $C$ denote setup and unit cost of the in-house process; $\beta_{1}$ stands for the relating factor of $\mathrm{K} \pi$ and $\mathrm{K} ; \beta_{2}$ represents the relating factor of $C_{\pi}$ and $C$ (where $-1<\beta_{1}<0$ and $\beta_{2}>0$ ).

The annual in-house fabrication rate is $P$ units, and a random nonconforming proportion $\mathrm{x}$ of the lot may be fabricated in uptime, with a rate $d=P x . A \theta$ portion of nonconforming items is categorized as scraps, and the other $(1-\theta)$ portion is identified as the re-workable items. In each cycle, a rework process begins when the regular fabrication ends (see Figure 1), and the annual rework rate is $P_{1}$ units. Furthermore, a $\theta_{1}$ portion of the reworked items fails and must be scrapped. The scrap items' production rate $\mathrm{d} 1$ during the rework time is $\mathrm{P}_{1} \theta_{1}$ (see the status of scraps in Fig. 2). No stock-out situations are permitted, so $\mathrm{P}-\mathrm{d}-\lambda>0$ must hold. The outsourcing products are received before the beginning of the entire batch's delivery time (Figure 1).

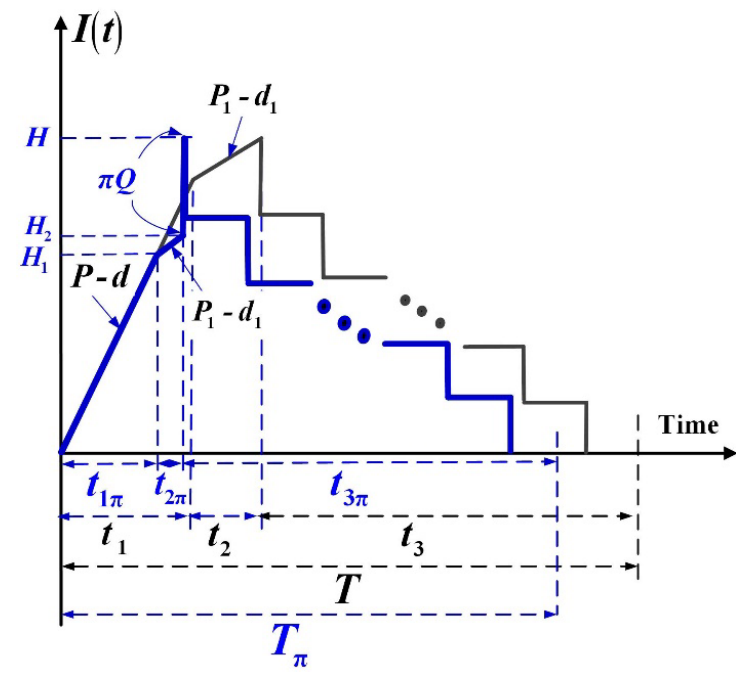

Figure 1: Status of perfect quality inventories in the proposed hybrid replenishment system (in blue) compared to that in a system with continuous distributing policy and pure in-house fabrication (in black)

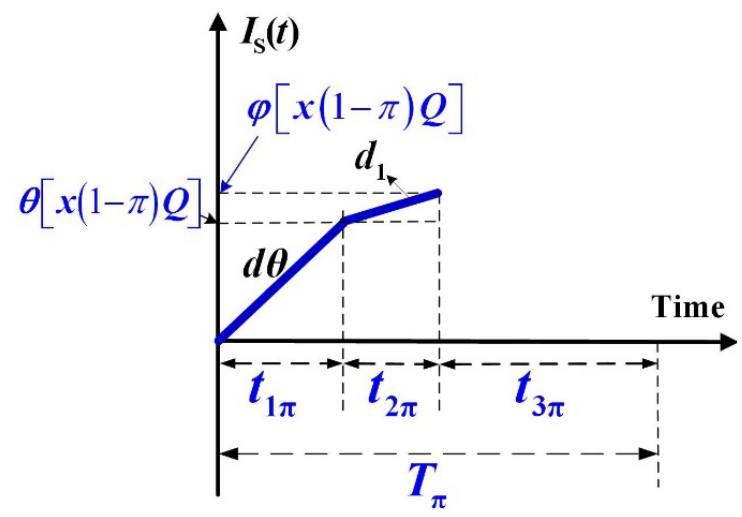

Figure 2: Status of scrap inventories in the proposed system

Istraživanja i projektovanja za priverdu ISSN 1451-4117 Journal of Applied Engineering Science Vol. 20, No. 1,2022 
Then, $\mathrm{n}$ fixed quantity installments of the batch are supplied to the buyer at a specified time interval in delivery time $t_{3 \pi}$. Figures 3 and 4 illustrate the status of on-hand inventories during $t_{3 \pi}$ at the producer side and in each cycle at the customer side, respectively.

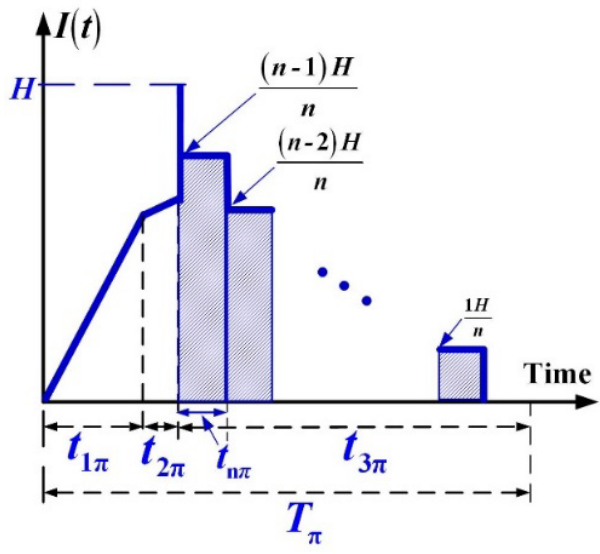

Figure 3: Status of perfect quality inventories during the shipping time

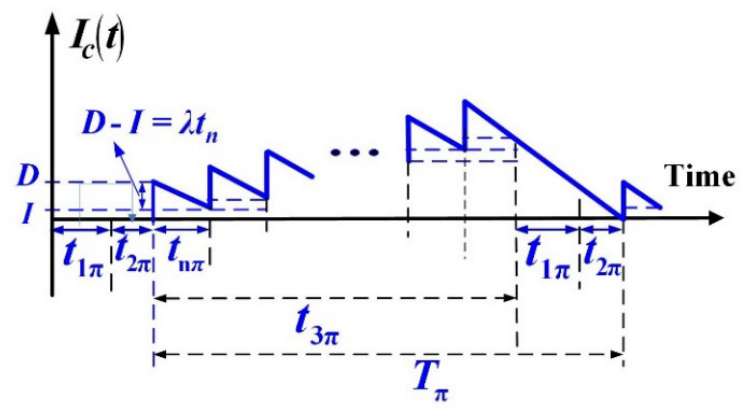

Figure 4: Status of stocks at customer's end in the proposed system

This study also employs the following notation: (1) $H_{1}$ : on-hand level of perfect quality stocks when the regular fabrication finishes, (2) $\mathrm{H}_{2}$ : on-hand level of perfect quality stocks when rework ends; (3) $\mathrm{H}$ : on-hand level of perfect quality stocks when outsourcing items are received; (4) $\mathrm{T}_{\pi}$ : replenishment cycle time; (5) CS: unit disposal cost; (6) $\mathrm{C}_{\mathrm{R}}$ : unit rework cost; (7) h: unit holding cost; (8) h1: holding cost per reworked item; (9) $\mathrm{K}_{1}$ : fixed shipping cost; (10) CT: unit shipping cost; (11) n: number of shipments per cycle; (12) $t_{n \pi}$ : specified time interval between any two shipments; (13) $h_{2}$ : unit holding cost at buyer side; (14) TC(Q, n): total cost per cycle; and (15) $E[T C U(Q, n)]:$ the expected system cost per unit time.

The definition of symbols used in the figures includes the following: $I(t)$ in Figure 1, means the status of on-hand perfect quality stocks at time $\mathrm{t}$; IS(t) in Figure 2, represents the status of on-hand scrap inventories at time $t ; I_{c}(t)$ in Figure 4, denotes the status of on-hand stocks at customer's side at time $t ; D$ is the number of products per delivery; $I$ is the leftover stocks during each $t_{n \pi}$ after demand $\lambda t_{n \pi}$ is met; $t_{1}$ means the uptime in the proposed system with $\pi=0 ; t_{2}$ stands for rework time in the proposed system with $\pi=0 ; t_{3}$ represents delivery time in the proposed system with $\pi=0$; and $\mathrm{T}$ denotes the cycle time in the proposed system with $\pi=0$.

\section{Formulations of the proposed supply-chain system}

From Figures 1 to 2, the following formulations are obtained from the in-house fabrication of $(1-\pi) \mathrm{Q}$ :

$$
\begin{aligned}
& t_{1 \pi}=\frac{(1-\pi) Q}{P}=\frac{H_{1}}{P-d} \\
& H_{1}=(P-d) t_{1 \pi} \\
& t_{2 \pi}=\frac{x[(1-\pi) Q](1-\theta)}{P_{1}} \\
& H_{2}=H_{1}+\left(P_{1}-d_{1}\right) t_{2 \pi} \\
& T_{\pi}=t_{1 \pi}+t_{2 \pi}+t_{3 \pi}=\frac{Q(1-x \varphi(1-\pi))}{\lambda} \\
& t_{3 \pi}=T_{\pi}-t_{1 \pi}-t_{2 \pi}
\end{aligned}
$$

The outsourcing products are scheduled to be received before the beginning of $t_{3 \pi}$, so the maximal on-hand perfect quality inventory level $\mathrm{H}$ is as follows:

$$
H=H_{2}+\pi Q
$$

The maximal number of nonconforming items $\mathrm{dt} 1 \mathrm{~m}$ and maximal scraps $\varphi[x(1-\pi) Q]$ in a cycle are given below:

$$
\begin{aligned}
& d t_{1 \pi}=x P t_{1 \pi}=x[(1-\pi) Q] \\
& \begin{aligned}
\varphi[x(1-\pi) Q]= & \theta[x(1-\pi) Q]+\theta_{1}(1-\theta)[x(1-\pi) Q]= \\
& =\left[\theta+(1-\theta) \theta_{1}\right] x[(1-\pi) Q]
\end{aligned}
\end{aligned}
$$

From Figure 3, total inventories in $t_{3 \pi}$ are [7] as follows:

$\left(\frac{1}{n^{2}}\right)\left(\sum_{i=1}^{n-1} i\right) H t_{3 \pi}=\left(\frac{1}{n^{2}}\right)\left[\frac{n(n-1)}{2}\right] H t_{3 \pi}=\left(\frac{n-1}{2 n}\right) H t_{3 \pi}$

From Figures 3 and 4 , the following formulations and total stocks at the customer side can be obtained [7] as follows:

$$
\begin{aligned}
& t_{n \pi}=\frac{t_{3 \pi}}{n} \\
& D=\frac{H}{n} \\
& I=D-\left(\lambda t_{n \pi}\right)
\end{aligned}
$$

Total inventories $=\left[\left(\frac{D+l}{2}\right) t_{n \pi}\right]+\left(\frac{n I}{2}\right)\left(t_{1 \pi}+t_{2 \pi}\right)$

$$
\begin{aligned}
& +\left[\frac{(D+I)+\left[(D+I)-\lambda t_{n \pi}\right]}{2} t_{n \pi}\right]+\left[\frac{(D+2 l)+\left[(D+2 l)-\lambda t_{n \pi}\right]}{2} t_{n \pi}\right]+ \\
& +\left[\frac{\left[D_{i}+(n-1) I_{i}\right]+\left[\left[D_{i}+(n-1) I_{i}\right]-\lambda t_{n \pi}\right]}{2} t_{n \pi}\right]
\end{aligned}
$$

Substitute Eqs. (11) to (13) in Eq. (14), and with additional derivations, the total inventories at the customer side become 
Total inventories $=\left(D-\frac{\lambda t_{n \pi}}{2}\right) t_{n \pi}+\left(D+l-\frac{\lambda t_{n \pi}}{2}\right) t_{n \pi}+$

$+\left(D+2 I-\frac{\lambda t_{n \pi}}{2}\right) t_{n \pi}+\ldots+\left(D+(n-1) I-\frac{\lambda t_{n \pi}}{2}\right) t_{n \pi}+\left(\frac{n I}{2}\right)\left(t_{1 \pi}+t_{2 \pi}\right)=$

$=n\left(D-\frac{\lambda t_{n \pi}}{2}\right) t_{n \pi}+\frac{n(n-1)}{2} I t_{n \pi}+\frac{n I}{2}\left(t_{1 \pi}+t_{2 \pi}\right)=\frac{1}{2}\left[\frac{H}{n} t_{3 \pi}+T_{\pi}\left(H-\lambda t_{3 \pi}\right)\right]$

\section{Cost analysis}

The fixed and variable outsourcing costs are as follows:

$K_{\pi}+C_{\pi}(\pi Q)=\left(1+\beta_{1}\right) K+\left(1+\beta_{2}\right) C(\pi Q)$

The in-house fabrication costs include setup and variable manufacturing costs, variable rework and disposal costs, fixed and variable shipping costs, holding cost during $t_{2 \pi}$, and total holding costs in $T_{\pi}$.

$K+C[(1-\pi) Q]+C_{R}(1-\theta)[x(1-\pi) Q]+h_{1} \frac{P_{1} t_{2 \pi}}{2}\left(t_{2 \pi}\right)+C_{S} \varphi[x(1-\pi) Q]+$ $+n K_{1}+C_{T}[Q(1-\varphi x(1-\pi))]+h\left[\frac{H_{1}+d t_{1 \pi}}{2}\left(t_{1 \pi}\right)+\frac{H_{1}+H_{2}}{2}\left(t_{2 \pi}\right)+\left(\frac{n-1}{2 n}\right) H t_{3 \pi}\right]$

The customer's side has the following holding cost:

$\frac{h_{2}}{2}\left[\frac{H}{n} t_{3 \pi}+T_{\pi}\left(H-\lambda t_{3 \pi}\right)\right]$

From Eqs. (16) to (18), $\mathrm{TC}(\mathrm{Q}, \mathrm{n})$ becomes as follows:

$T C(Q, n)=\left(1+\beta_{1}\right) K+\left(1+\beta_{2}\right) C(\pi Q)+K+C[(1-\pi) Q]+C_{R}(1-\theta)[x(1-\pi) Q]$

$+C_{S} \varphi[x(1-\pi) Q]+n K_{1}+C_{T}[Q(1-\varphi x(1-\pi))]+h_{1} \frac{P_{1} t_{2 \pi}}{2}\left(t_{2 \pi}\right)$

$+\frac{h_{2}}{2}\left[\frac{H}{n} t_{3 \pi}+T_{\pi}\left(H-\lambda t_{3 \pi}\right)\right]+h\left[\frac{H_{1}+d t_{1 \pi}}{2}\left(t_{1 \pi}\right)+\frac{H_{1}+H_{2}}{2}\left(t_{2 \pi}\right)+\left(\frac{n-1}{2 n}\right) H t_{3 \pi}\right]$

The expected value of $\mathrm{x}$ is used to consider the nonconforming rate's randomness and by substituting all relevant variables from Eqs. (1) to (9) into Eq. (19), E[T$\mathrm{CU}(\mathrm{Q}, \mathrm{n})]$ can be found as follows:

$E[\operatorname{TCU}(Q, n)]=\frac{E[T C(Q, n)]}{E[T]}=\frac{\lambda}{Q}\left[\left(1+\beta_{1}\right) K+K+n K_{1}\right] E_{0}$

$+\lambda\left[\left(1+\beta_{2}\right) C \pi+C(1-\pi)\right] E_{0}+\lambda\left[C_{R}(1-\pi)(1-\theta)+C_{S} \varphi(1-\pi)\right] E_{1}+C_{T} \lambda$

$+\frac{Q}{2}\left\{\begin{array}{l}\lambda E[x](1-\pi) E_{2}\left[h_{1}(1-\theta)-h\right]+h\left[\frac{1}{E_{0}^{2}}+\frac{(1-\pi) \lambda}{P}(\varphi E[x](1-\pi)-\pi)+\lambda E_{2}(1-2 \pi)\right] \\ +h_{2}\left[\frac{1}{E_{0}}\left(\frac{(1-\pi) \lambda}{P}+\lambda E_{2}\right)\right]+\left(h_{2}-h\right)\left(\frac{1}{n}\right)\left[\frac{1}{E_{0}}\left(\frac{1}{E_{0}}-\frac{(1-\pi) \lambda}{P}-\lambda E_{2}\right)\right]\end{array}\right\} E_{0}$

where

$E_{0}=\frac{1}{1-\varphi E[x](1-\pi)} ; E_{1}=\frac{E[x]}{1-\varphi E[x](1-\pi)} ; E_{2}=\frac{E[x](1-\pi)(1-\theta)}{P_{1}}$

\section{Determining the optimal replenishment batch size and deliveries}

Apply the Hessian matrix equations [30] to Eq. (20) to first prove that $E[\operatorname{TCU}(Q, n)]$ is convexity, i.e., to show the following equation holds:
$\left[\begin{array}{ll}Q & n\end{array}\right] \cdot\left(\begin{array}{ll}\frac{\partial^{2} E[\operatorname{TCU}(Q, n)]}{\partial Q^{2}} & \frac{\partial^{2} E[\operatorname{TCU}(Q, n)]}{\partial Q \partial n} \\ \frac{\partial^{2} E[T C U(Q, n)]}{\partial Q \partial n} & \frac{\partial^{2} E[\operatorname{TCU}(Q, n)]}{\partial n^{2}}\end{array}\right) \cdot\left[\begin{array}{l}Q \\ n\end{array}\right]>0$

Detailed derivation of the Hessian matrix equation [30] is exhibited in Appendix A. Substitute Eqs. (A-2), (A-4), and (A-5) in Eq. (21), one obtains Eq. (22):

$\left[\begin{array}{ll}Q & n\end{array}\right] \cdot\left(\begin{array}{ll}\frac{\partial^{2} E[T C U(Q, n)]}{\partial Q^{2}} & \frac{\partial^{2} E[\operatorname{TCU}(Q, n)]}{\partial Q \partial n} \\ \frac{\partial^{2} E[T C U(Q, n)]}{\partial Q \partial n} & \frac{\partial^{2} E[T C U(Q, n)]}{\partial n^{2}}\end{array}\right) \cdot\left[\begin{array}{l}Q \\ n\end{array}\right]=\frac{2 \lambda}{Q}\left[\left(1+\beta_{1}\right) K+K\right] E_{0}>0$

Since $E_{0}, K, \lambda, Q$, and $\left(1+\beta_{1}\right)$ are all positive, Eq. (22) results positive. Hence, $E[T C U(Q, n)]$ is strictly convex, for all $Q$ and $n$ different from zero. To seek the optimal batch size and frequency of shipments per cycle, we can set the first derivatives concerning $n$ and $Q$ (i.e., Eqs. (A1 ) and (A-3)) equal to zero and solve the specific linear system and find the following:

$$
Q^{*}=\sqrt{\frac{2 \lambda\left[\left(2+\beta_{1}\right) K+n K_{1}\right]}{\lambda E[x](1-\pi) E_{2}\left[h_{1}(1-\theta)-h\right]+h\left[\frac{1}{E_{0}^{2}}+\frac{(1-\pi) \lambda}{P}(\varphi E[x](1-\pi)-\pi)+\lambda E_{2}(1-2 \pi)\right]+}}
$$

and

$$
n^{*}=\sqrt{\frac{\left(2+\beta_{1}\right) K\left(h_{2}-h\right)\left(\frac{1}{E_{0}}-\frac{(1-\pi) \lambda}{P}-\lambda E_{2}\right)}{K_{1}\left\{\begin{array}{l}
\lambda E[x](1-\pi) E_{2}\left[h_{1}(1-\theta)-h\right] E_{0}+h_{2}\left(\frac{(1-\pi) \lambda}{P}+\lambda E_{2}\right)+ \\
+h\left[\frac{1}{E_{0}}+\frac{(1-\pi) \lambda}{P}(\varphi E[x](1-\pi)-\pi) E_{0}+\lambda E_{2}(1-2 \pi) E_{0}\right]
\end{array}\right\}}}
$$

It is worth noting that the result of the number of shipments per cycle obtained in Eq. (24) is a real number; however, in real-life application, it should only be an integer. The following process helps find the optimal integer value $n^{*}$ : First, find two adjacent integers of $n$ (as obtained from Eq. (24)), let $n+$ be the smallest integer greater than $n$ and $n$ - denote the largest integer less than $\mathrm{n}$. Then, substitute $\mathrm{n}-$ and $\mathrm{n}+$ in Eq. (23) to find their corresponding values of $Q$, and apply the resulting $(Q, n+)$ and (Q, n-) in Eq. (20) to obtain their respective system costs. Lastly, select the one that has a minimum value of $E[T C U(Q, n)]$ as our optimal operating policy of $\left(Q^{*}, n^{*}\right)$.

\section{Numerical illustration, sensitivity analyses, and discussion}

Applying Eqs. (23) and (24), one finds the optimal $Q^{*}=1141$ and $n^{*}=3$. Computation of Eq. (20) with $Q^{*}$ and $n^{*}$, one obtains $E\left[T C U\left(Q^{*}, n^{*}\right)\right]=\$ 516,142$. The combined impacts of $Q$ and $n$ on the $E[T C U(Q, n)]$ (for $\pi=0.4$ ) are exposed in Figure 5. 


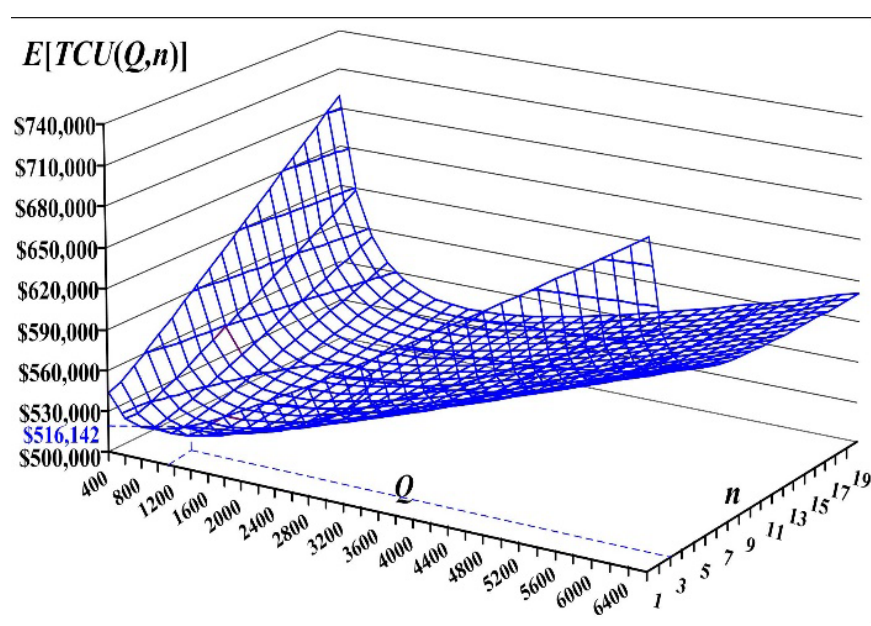

Figure 5: Combined impacts of variations in $Q$ and $n$ on $E[T C U(Q, n)]$

Effects of different outsourcing portion $\pi$ on various system parameters are analyzed and displayed in Table 1. It is noted that for the case of outsourcing all products (i.e., $\pi=1$ ), $E\left[\operatorname{TCU}\left(Q^{*}, n^{*}\right)\right]=\$ 519,926$, which enables us to locate the critical ratio of $\pi=0.503$ for the make-or-buy decision (see Figure 6). It indicates that as $\pi$ increases, in-house machine utilization decreases accordingly (see Figure 7). In our example, at $\pi=0.40$, the utilization declines slightly over $40 \%$ (i.e., $40.5 \%$, refer to Table 1 for details).

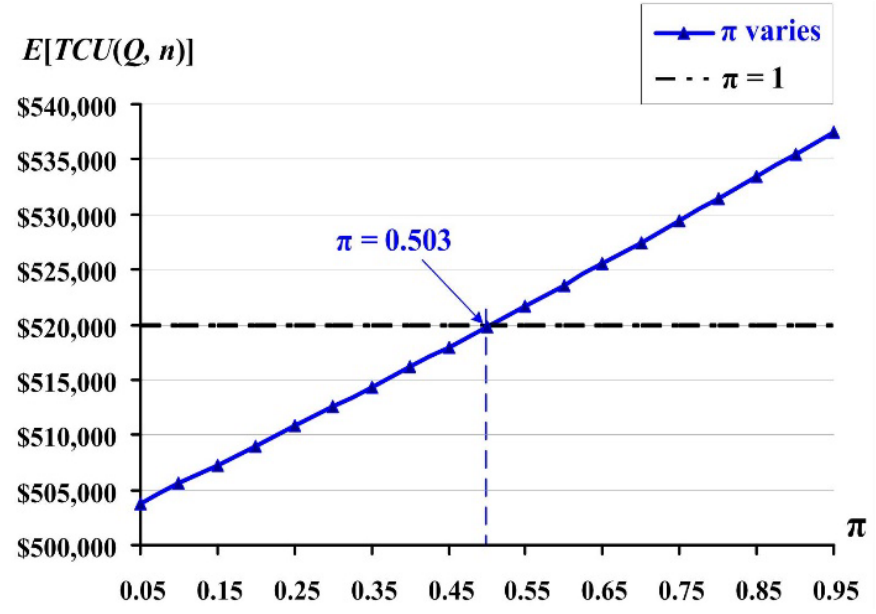

Figure 6: Exploration of the critical ratio of $\pi$ for make-or-buy decision

The joint influences of changes in $\beta_{2}$ and $\pi$ on $E[T C U(Q$, $\mathrm{n})$ ] are exhibited in Figure 8. It shows that asm increases, $\mathrm{E}[\mathrm{TCU}(\mathrm{Q}, \mathrm{n})]$ rises significantly. And as unit outsourcing cost factor $\beta_{2}$ goes up, $E[T C U(Q, n)]$ increases, especially knowingly growth as $\pi$ rises.

Additional investigation exposes the combined influences of variations in $Q$ and $\beta_{2}$ on $E[T C U(Q, n)]$ when $\pi=0.4$ (see Figure 9). It can be seen that as unit outsourcing cost factor $\beta_{2}$ increases, the optimal lot-size $Q^{*}$ chang-

Table 1: Effects of different outsourcing portion $\pi$ on various system parameters

\begin{tabular}{|c|c|c|c|c|c|c|c|c|c|c|c|}
\hline$\pi$ & $\mathrm{n}^{*}$ & $\mathbf{Q}^{*}$ & $\begin{array}{l}\text { Outsourcing } \\
\text { Cost }\end{array}$ & $\begin{array}{l}\text { In-house } \\
\text { Produc- } \\
\text { tion Cost }\end{array}$ & $\begin{array}{l}\text { Total } \\
\text { Delivery } \\
\text { Cost }\end{array}$ & $\begin{array}{l}\text { Customer's } \\
\text { Stock Hold- } \\
\text { ing Cost }\end{array}$ & $\begin{array}{c}\mathrm{E}[\mathrm{T}- \\
\mathrm{CU}\left(\mathbf{Q}^{*},\right. \\
\left.\left.\mathrm{n}^{*}\right)\right]\end{array}$ & $\begin{array}{l}\text { Cost In- } \\
\text { crease } \\
\%\end{array}$ & $\begin{array}{l}T^{*}(\text { in } \\
\text { year) }\end{array}$ & $\begin{array}{l}\text { Machine Utili- } \\
\text { zation }\left(\mathrm{t}_{1}+\mathrm{t}_{2}\right) / \mathrm{T}^{*}\end{array}$ & $\begin{array}{c}\text { Utilization } \\
\text { Decrease } \\
\%\end{array}$ \\
\hline 0 & 2 & 869 & $\$ 0$ & $\$ 463,969$ & $\$ 9,508$ & $\$ 21,777$ & $\$ 495,253$ & $0.00 \%$ & 0.2131 & 0.20387 & $0 \%$ \\
\hline 0.05 & 2 & 971 & & $\$ 440,201$ & & & & & & & $-5.1 \%$ \\
\hline 0.10 & 2 & 980 & 5,066 & 417,793 & $\$ 8,646$ & $\$ 24,056$ & $\$ 505,561$ & $2.08 \%$ & 0.2407 & 8313 & $-10.2 \%$ \\
\hline 0.15 & 3 & 1087 & $0, r 00$ & $\$ 396,556$ & $\$ 10,973$ & $\$ 20,969$ & $\$ 507,288$ & $2.43 \%$ & 0.2675 & 17279 & $-15.2 \%$ \\
\hline 0.20 & 3 & 1098 & & & $\$ 10,874$ & & 509,021 & $2.78 \%$ & & & \\
\hline 0.25 & 3 & 1109 & $\$ 127,221$ & $\$ 352,156$ & $\$ 10,779$ & $\$ 20,615$ & $\$ 510,772$ & $3.13 \%$ & 0.2734 & 217 & $-25.4 \%$ \\
\hline 0.30 & 3 & 1120 & 51,370 & $\$ 330,063$ & $\$ 10,686$ & $\$ 20,423$ & $\$ 512,542$ & $3.49 \%$ & 0.2763 & & $-30.4 \%$ \\
\hline 0.35 & 3 & 1131 & & & & & & & & & \\
\hline 0.40 & 3 & 1141 & $\$ 199,534$ & $\$ 286,093$ & $\$ 10,512$ & $\$ 20,003$ & $\$ 516,142$ & $4.22 \%$ & 0.2820 & 2138 & $-40.5 \%$ \\
\hline 0.45 & 3 & 1151 & & $\$ 264,218$ & $\$ 10,429$ & $\$ 19,776$ & $\$ 517,973$ & $4.59 \%$ & 0.2847 & 116 & $-45.5 \%$ \\
\hline 0.50 & 3 & 1161 & $\$ 247,521$ & $\$ 242,416$ & $\$ 10,351$ & & $\$ 519,825$ & $4.96 \%$ & 0.2874 & .10096 & $-50.5 \%$ \\
\hline 0.55 & 3 & 1170 & $\$ 271,449$ & $\$ 220,688$ & $\$ 10,275$ & $\$ 19,286$ & $\$ 521,699$ & $5.34 \%$ & 0.2900 & 078 & $-55.5 \%$ \\
\hline 0.60 & 3 & 1179 & $\$ 295,333$ & & $\$ 10,204$ & & $\$ 523,596$ & $5.72 \%$ & 0.2925 & & $-60.5 \%$ \\
\hline 0.65 & 3 & 1188 & & & $\$ 10,136$ & & $\$ 525,516$ & & 0.2950 & & \\
\hline 0.70 & 3 & 1196 & $\$ 342,971$ & $\$ 155,956$ & $\$ 10,072$ & $\$ 18,459$ & $\$ 527,459$ & $6.50 \%$ & 0.2973 & 0.06034 & $-70.4 \%$ \\
\hline 0.75 & 3 & 1204 & $\$ 366,726$ & $\$ 134,530$ & $\$ 10,012$ & & $\$ 529,427$ & $6.90 \%$ & 0.2995 & 0.05024 & $-75.4 \%$ \\
\hline 0.80 & 3 & 1211 & $\$ 390,437$ & $\$ 113,180$ & $\$ 9,956$ & & $\$ 531,419$ & $7.30 \%$ & 0.3017 & 0.04015 & $-80.3 \%$ \\
\hline 0.85 & 4 & 1328 & $\$ 413,698$ & $\$ 93,195$ & $\$ 11,668$ & $\$ 14,865$ & $\$ 533,426$ & $7.71 \%$ & 0.3310 & 0.03009 & $-85.2 \%$ \\
\hline 0.90 & 4 & 1336 & $\$ 437,321$ & $\$ 72,053$ & $\$ 11,597$ & $\$ 14,427$ & $\$ 535,399$ & $8.11 \%$ & 0.3334 & 0.02004 & $-90.2 \%$ \\
\hline 0.95 & 4 & 1344 & $\$ 460,902$ & $\$ 50,989$ & $\$ 11,532$ & $\$ 13,976$ & $\$ 537,399$ & $8.51 \%$ & 0.3357 & 0.01001 & $-95.1 \%$ \\
\hline 1 & 2 & 654 & $\$ 495,061$ & $\$ 0$ & $\$ 11,787$ & $\$ 13,078$ & $\$ 519,926$ & $4.98 \%$ & 0.1635 & 0.00000 & $-100.0 \%$ \\
\hline
\end{tabular}


es a little, but the system cost $E[T C U(Q, n)]$ increases significantly. And at $\beta_{2}=0.2$ as our example assumes, $Q^{*}=1141$.

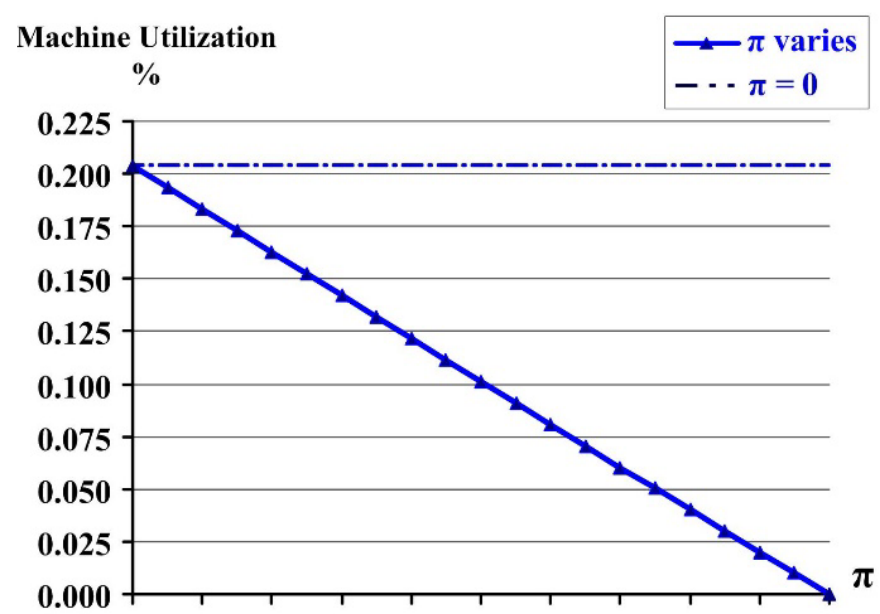

$\begin{array}{lllllllllll}0.00 & 0.10 & 0.20 & 0.30 & 0.40 & 0.50 & 0.60 & 0.70 & 0.80 & 0.90 & 1.00\end{array}$

Figure 7: Effect of variations in $\pi$ on in-house utilization

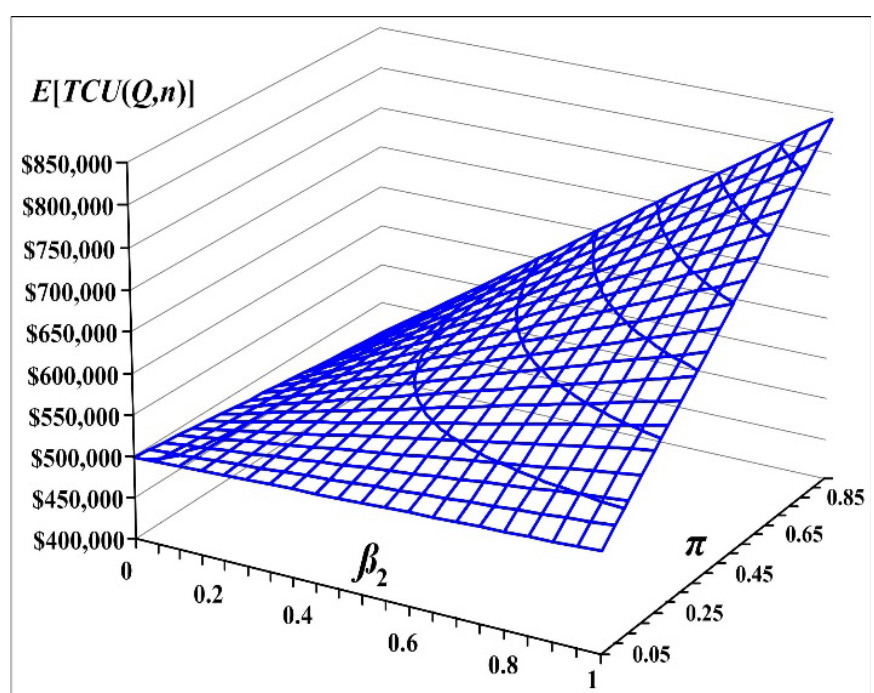

Figure 8: Joint influences of changes in $\beta_{2}$ and $\pi$ on $E[T C U(Q, n)]$

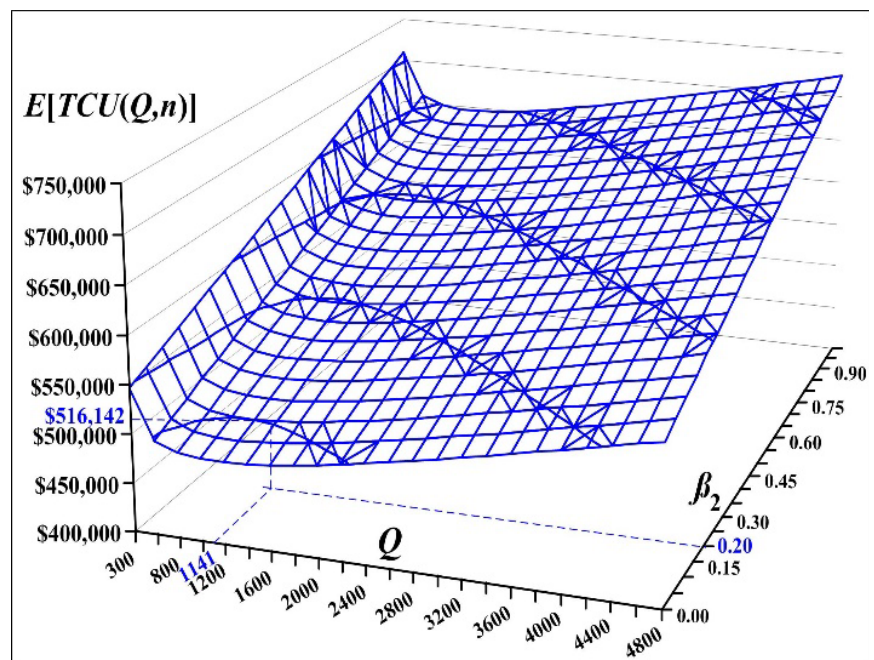

Figure 9: Combined influences of variations in $Q$ and $\beta_{2}$ on $E[T C U(Q, n)]$
Moreover, the effects of $x$ and different $\varphi$ on the system cost $\mathrm{E}[\mathrm{TCU}(\mathrm{Q}, \mathrm{n})]$ are demonstrated in Figure 10. It specifies that as $x$ increases, $E[T C U(Q, n)]$ knowingly increases, simply due to quality assurance cost rises. As the overall scrap rate $\varphi$ rises, the system cost $E[T C U(Q$, $n)$ ] increases as expected.

Finally, the proposed system enables us to explore the critical ratio of $\varphi$ for the make-or-buy decision (see Figure 11). In our numerical example, the further analytical result indicates that for a pure in-house fabrication system (i.e., $\pi=0$ ), if the overall scrap rate $\varphi$ exceeds 0.626 , then switch to a 'buy' system (i.e., $\pi=1$ ) becomes a better decision in saving system cost.

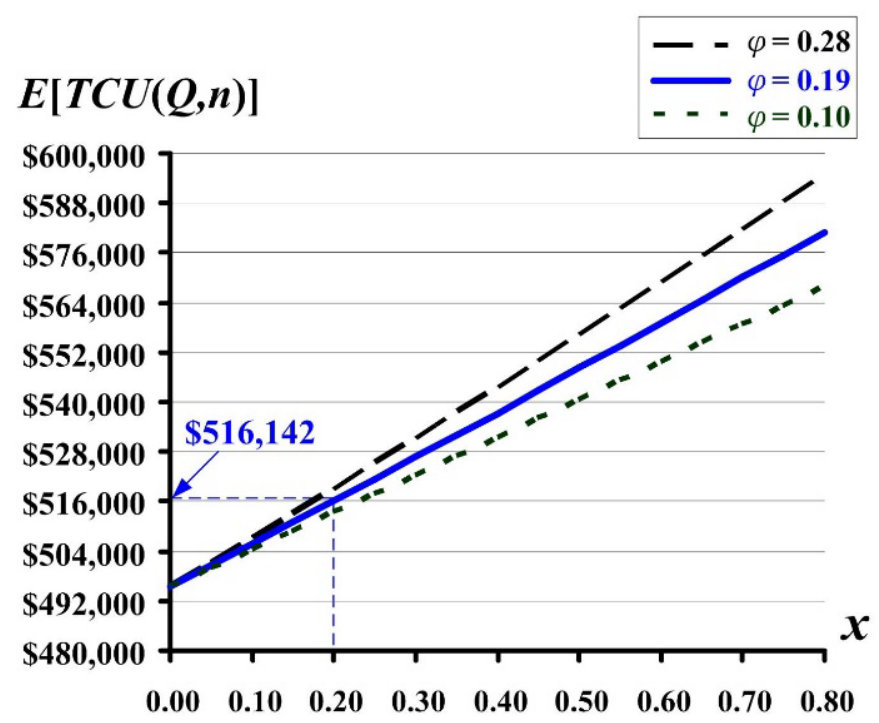

Figure 10: Effects of variations in $x$ and different $\varphi$ on $E[T C U(Q, n)]$

\section{$E[T C U(Q, n)]$}

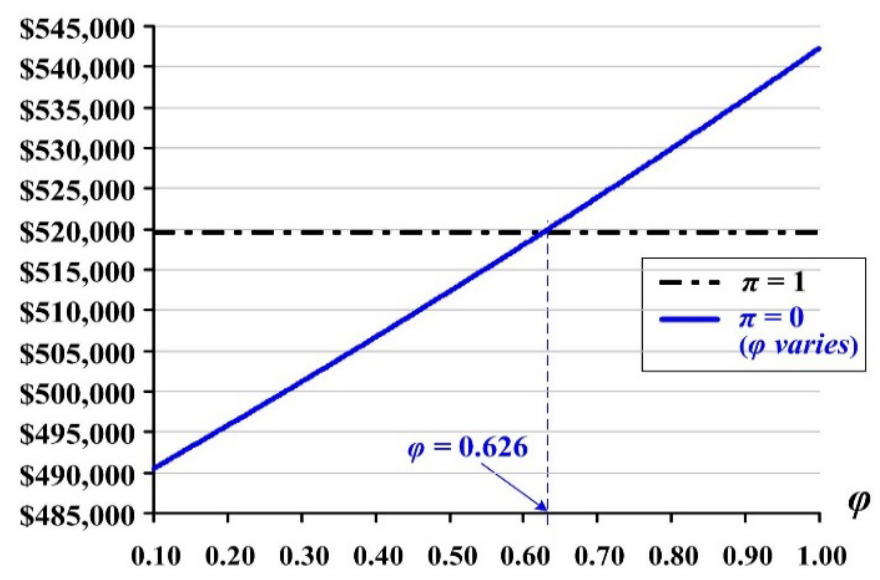

Figure 11: Investigation of the critical ratio of $\varphi$ for make-or-buy decision

\section{CONCLUSIONS}

This paper explores an intra-supply chain type of production-shipment problem, featuring outsourcing, in-house product quality assurance, and discontinuous multi-shipment products issuing policy. A mathematical model is constructed to describe the proposed problem precisely. 
By the use of optimization techniques, the optimal production-shipment policy is derived. This study demonstrates the applicability of research results through a numerical example and reveals diverse unseen important information of this specific problem. The latter, main findings of the present study, includes (1) effects of different outsourcing portion $\pi$ on various system parameters (Table 1); (2) exploring the critical ratio of $\pi$ for make-or-buy decision making (Fig. 6); (3) effects of variations in $\pi$ on in-house machine utilization (Fig. 7); (4) joint effects of variations in $\beta 2$ and $\pi$ on system cost (Fig. 8); (5) joint effects of variations in $Q$ and $\beta 2$ on system cost (Fig. 9); (6) effects of variations in $x$ and different $\varphi$ on system cost (Fig. 10); and (7) investigating the critical ratio of $\varphi$ for make-or-buy decision making (Fig. 11), etc. Without an in-depth investigation of such a specific problem, the crucial managerial information mentioned above is inaccessible. For future work, one may explore the effect of probabilistic demand on the same problem.

\section{ACKNOWLEDGMENTS}

The authors thank the Ministry of Science and Technology of Taiwan for its kind support to this study under contract number: MOST-104-2410-H-324-008-MY2.

\section{REFERENCES}

1. Leavy, B. (1996). Outsourcing strategy and a learning dilemma. Production and Inventory Management Journal, 37(4), 50-54.

2. Chalos, P., Sung, J. (1998). Outsourcing decisions and managerial incentives. Decision Sciences, 29(4), 901-917. https://doi.org/10.1111/j.1540-5915.1998. tb00881.x

3. Levina, N., Ross, J.W. (2003). From the vendor's perspective: Exploring the value proposition in information technology outsourcing. MIS Quarterly: Management Information Systems, 27(3), 331-364. https://doi.org/10.2307/30036537

4. Serrato, M.A., Ryan, S.M., Gaytán, J. (2007). A Markov decision model to evaluate outsourcing in reverse logistics. International Journal of Production Research, 45(18-19), 4289-4315. https://doi. org/10.1080/00207540701450161

5. Proff, H. (2011). Where differentiating automobile manufacturers go wrong: Strategic challenges posed by increased outsourcing. International Journal of Automotive Technology and Management, 11(1), 1635. DOI: 10.1504/IJATM.2011.038119

6. Balachandran, K.R., Wang, H-W., Li, S-H., Wang, T. (2013). In-house capability and supply chain decisions. Omega, 41(2), 473-484. https://doi. org/10.1016/j.omega.2012.01.003
7. Chiu, Y-S.P., Liang, G-M., Chiu, S.W. (2016). Solving a fabrication lot-size and shipping frequency problem with an outsourcing policy and random scrap. Mathematical and Computational Applications, 21(4), Article No. 45. https://doi.org/10.3390/mca21040045

8. 8. Skowronski, K., Benton Jr., W.C. (2018). The influence of intellectual property rights on poaching in manufacturing outsourcing. Production and Operations Management, 27(3), 531-552. https://doi. org/10.1111/poms. 12813

9. 9. Cortinhal, M.J., Lopes, M.J., Melo, M.T. (2019). A multi-stage supply chain network design problem with in-house production and partial product outsourcing. Applied Mathematical Modelling, 70, 572594. https://doi.org/10.1016/j.apm.2019.01.046

10. 10. Thongrawd, C., Skulitsariyaporn, C., Sirisopana, S., Chomchom, N. (2020). The impact of the strategic supplier partnership, and strategic outsourcing on the supply chain performance: The mediating role of customer relationship. International Journal of Supply Chain Management, 9(2), 562-571. https:// ojs.excelingtech.co.uk/index.php/IJSCM/article/ view/4661

11. 11. Chiu, Y-S.P., Sung, P-C., Chiu, V. (2020). A twophase solution approach for a manufacturing-distribution problem with rework, outsourcing, and multi-shipment policy. Journal of Applied Engineering Science, 18(4), 505-509. https://doi.org/10.5937/ jaes0-26156

12. Rosenblatt, M.J., Lee, H. L. (1986). Economic production cycles with imperfect production processes. IIE Transactions, 18, 48-55. https://doi. org/10.1080/07408178608975329

13. Rahim, M.A., Ben-Daya, M. (2001). Joint determination of production quantity, inspection schedule and quality control for imperfect process with deteriorating products. Journal of the Operational Research Society, 52, 1370-1378. https://doi.org/10.1057/palgrave.jors.2601238

14. Ojha, D., Sarker, B.R., Biswas, P. (2007). An optimal batch size for an imperfect production system with quality assurance and rework. International Journal of Production Research, 45(14), 3191-3214. https:// doi.org/10.1080/00207540600711853

15. Sana, S.S. (2010). A production-inventory model in an imperfect production process. European Journal of Operational Research, 200(2), 451-464. https:// doi.org/10.1016/j.ejor.2009.01.041 
16. Adazabra, A.N., Viruthagiri, G., Shanmugam, N. (2018). Manufacture of lightweight clay bricks with improved thermal insulation properties via the incorporation of spent shea waste. Journal of Applied Research and Technology, 16(3), 186-203. https://jart. icat.unam.mx/index.php/jart/article/view/717

17. Tannady, H., Gunawan, E., Nurprihatin, F., Wilujeng, F.R. (2019). Process improvement to reduce waste in the biggest instant noodle manufacturing company in South East Asia. Journal of Applied Engineering Science, 17(2), 203-212. https://doi.org/10.5937/ jaes17-18951

18. Ben Fathallah, B., Saidi, R., Dakhli, C., Belhadi, S., Yallese, M.A. (2019). Mathematical modelling and optimization of surface quality and productivity in turning process of aisi 12114 free-cutting steel. International Journal of Industrial Engineering Computations, 10(4), 557-576. http://dx.doi.org/10.5267/j. ijiec.2019.3.001

19. Pinto, G., Silva, F.J.G., Fernandes, N.O., Casais, R., Baptista, A., Carvalho, C., (2020). Implementing a maintenance strategic plan using TPM methodology, International Journal of Industrial Engineering and Management, 11(3), 192-204. http://dx.doi. org/10.24867/IJIEM-2020-3-264

20. Taft, E.W. (1918). The most economical production lot. Iron Age, 101, 1410-1412.

21. Goyal, S.K. (1977). Integrated inventory model for a single supplier - single customer problem. International Journal of Production Research, 15(1), $107-$ $111 \mathrm{https} / / /$ doi.org/10.1080/00207547708943107

22. Banerjee, A. (1986). A joint economic-lot-size model for purchaser and vendor. Decision Sciences, 17(3), 292-311. https://doi.org/10.1111/j.1540-5915.1986. tb00228.x

23. Viswanathan, S. (1998). Optimal strategy for the integrated vendor-buyer inventory model. European Journal of Operational Research, 105(1), 38-42. https://doi.org/10.1016/S0377-2217(97)00032-5

24. Sarker, B.R., Diponegoro, A. (2009). Optimal production plans and shipment schedules in a supply-chain system with multiple suppliers and multiple buyers. European Journal of Operational Research, 194(3), 753-773.https://doi.org/10.1016/j.ejor.2008.01.025

25. Chiu, S.W., Chen, H.-M., Lin, H.-D., Chiu, Y.-S.P. (2018). Optimization of an intra-supply chain system with unreliable production facility. Journal of Applied Engineering Science, 16(2), 192-201. https://scindeks.ceon.rs/article. aspx?artid=1451-41171802192C

26. Buriticá, N.C., Escobar, J.W., Gutiérrez, R. (2018). Supply network design by using clustering and mixed integer programming, International Journal of Industrial Engineering and Management, 9(2), 59-68. https://www.researchgate.net/publication/327882621
27. López-Ruíz, S., Carmona-Benítez, R.B. (2019). The design of a liquefied natural gas (LNG) distribution network of a company operating in Mexico. Journal of Applied Research and Technology, 17(4), 213249. https://jart.icat.unam.mx/index.php/jart/article/ view/818

28. Bouziyane, B., Dkhissi, B., Cherkaoui, M. (2020). Multiobjective optimization in delivering pharmaceutical products with disrupted vehicle routing problem. International Journal of Industrial Engineering Computations, 11(2), 299-316. http://dx.doi.org/10.5267/j. ijiec.2019.7.003

29. Shavdinova, M., Aronson, K., Borissova, N. (2020). Development of condenser mathematical model for research and development of ways to improve its efficiency. Journal of Applied Engineering Science, 18(4), 578-585.https://aseestant.ceon.rs/index.php/ jaes/article/view/27517

30. Rardin, R.L. (1998). Optimization in Operations Research. Prentice-Hall, New Jersey, 739-741.

\section{NUMERICAL ILLUSTRATION}

To show the applicability of research results, this section provides a numerical example with the following system parameters:

$\lambda=4,000$ units,

$\mathrm{P}=20,000$ units,

$\mathrm{K}=\$ 5,000$ per run,

$\mathrm{C}=\$ 100$ per product fabricated in-house,

$\mathrm{h}=\$ 30$ per item,

$\pi=0.4$, the outsourcing proportion of replenishment batch,

$K_{\pi}=\$ 1,500$, the fixed cost per outsourcing items,

$\beta_{1}=-0.7$,

$\mathrm{C}_{\pi}=\$ 120$, unit outsourcing cost,

$\beta_{2}=0.2$,

$x=$ over the interval of $[0,0.2]$, a random variable that adheres to a uniform distribution,

$\theta=0.1$, the scrap portion of faulty items,

$P_{1}=5000$ units per year, the reworking rate,

$\mathrm{C}_{\mathrm{R}}=\$ 60$ per reworked item,

$\mathrm{h}_{1}=\$ 40$ per reworked item per year,

$\theta_{1}=0.1$, the scrap portion of reworked items,

$\mathrm{C}_{\mathrm{s}}=\$ 20$, unit disposal cost,

$\mathrm{K}_{1}=\$ 800$, the fixed cost per delivery,

$\mathrm{C}_{\mathrm{T}}=\$ 0.5$, unit delivery cost,

$h_{2}=\$ 80$ per item per year, holding cost at customer side.

\section{APPENDIX A}

The detailed derivations of the Hessian Matrix Equations. The following partial derivatives are obtained from Eq. (20): 
$\frac{\partial E[T C U(Q, n)]}{\partial Q}=\frac{-\lambda}{Q^{2}}\left[\left(1+\beta_{1}\right) K+K+n K_{1}\right] E_{0}+$

$+\frac{1}{2}\left\{\begin{array}{l}\lambda E[x](1-\pi) E_{2}\left[h_{1}(1-\theta)-h\right]+h\left[\frac{1}{E_{0}^{2}}+\frac{(1-\pi) \lambda}{P}(\varphi E[x](1-\pi)-\pi)+\lambda E_{2}(1-2 \pi)\right]+ \\ +h_{2}\left[\frac{1}{E_{0}}\left(\frac{(1-\pi) \lambda}{P}+\lambda E_{2}\right)\right]+\left(h_{2}-h\right)\left(\frac{1}{n}\right)\left[\frac{1}{E_{0}}\left(\frac{1}{E_{0}}-\frac{(1-\pi) \lambda}{P}-\lambda E_{2}\right)\right]\end{array}\right\} E_{0}$

$\frac{\partial^{2} E[\operatorname{TCU}(Q, n)]}{\partial Q^{2}}=\frac{2 \lambda}{Q^{3}}\left[\left(1+\beta_{1}\right) K+K+n K_{1}\right] E_{0}$

$\frac{\partial E[\operatorname{TCU}(Q, n)]}{\partial n}=\frac{\lambda}{Q} K_{1} E_{0}+\frac{Q}{2}\left(h_{2}-h\right)\left(\frac{-1}{n^{2}}\right)\left(\frac{1}{E_{0}}-\frac{(1-\pi) \lambda}{P}-\lambda E_{2}\right)$

$\frac{\partial^{2} E[\operatorname{TCU}(Q, n)]}{\partial n^{2}}=\left(h_{2}-h\right)\left(\frac{Q}{n^{3}}\right)\left(\frac{1}{E_{0}}-\frac{(1-\pi) \lambda}{P}-\lambda E_{2}\right)$

$\frac{\partial E[\operatorname{TCU}(Q, n)]}{\partial Q \partial n}=\frac{-\lambda}{Q^{2}} K_{1} E_{0}+\frac{\left(h_{2}-h\right)}{2}\left(\frac{-1}{n^{2}}\right)\left(\frac{1}{E_{0}}-\frac{(1-\pi) \lambda}{P}-\lambda E_{2}\right)$ 